\title{
Associations Among School and Friendship Identity in Adolescence and Romantic Relationships and Work in Emerging Adulthood
}

Emerging Adulthood

2014, Vol. 2(1) 6-16

(C) 2013 Society for the

Study of Emerging Adulthood

and SAGE Publications

Reprints and permission:

sagepub.com/journalsPermissions.nav DOI: $|0.1| 77 / 21676968 \mid 351585$ |

ea.sagepub.com

(S)AGE

\author{
Susan Branje', Lydia Laninga-Wijnen', Rongqin $\mathbf{Y u}^{\prime}$, \\ and Wim Meeus ${ }^{1,2}$
}

\begin{abstract}
This study examined the interrelations between employment status and romantic relationship status, work and romantic relationship identity in emerging adulthood, and school and friendship identity in adolescence. Dutch participants $(N=1,026)$ from two age cohorts (16-year-old cohort comprised 735 participants and 20-year-olds comprised 29I, at Time I) reported about school and friendship identity during adolescence, and about status of and identification with work and romantic relationships during emerging adulthood 5 years later. Employment status and romantic relationship status were significantly related to each other. Employment status was also significantly related to relational identity, and relationship status was significantly related to work identity. Moreover, work and romantic relationship identity, but not employment status and romantic relationship status, could be predicted by school and friendship identity in adolescence. These results confirm the interdependence of role transitions in emerging adulthood and suggest that the base of the successful attainment of these transitions is laid in adolescence.
\end{abstract}

\section{Keywords}

romantic relationship identity, work identity, emerging adulthood, school identity, friendship identity

During emerging adulthood, individuals face two important developmental tasks: making the transition from school to work and forming romantic relationships (Erikson, 1968). These role transitions have important effects on many aspects of young people's lives and well-being (Havighurst, 1972; Schulenberg, Bryant, \& O’Malley, 2004). These transitions in different domains are interdependent: Whether or not one has made the transition into one role might affect the probability of making the transition to another role as well as how one handles other roles (Elder, 1998; Erikson, 1968; Marini, 1985). For example, being in a romantic relationship might encompass implicit or explicit requirements or obligations to the partner, such as financially taking care of the partner or building a household together, that might affect the transition and commitment to work (Arnett, 1998). Moreover, during adolescence, young people make many decisions that prepare them for adulthood and affect their future lives (Crockett \& Beal, 2012). This suggests that identity development in adolescence might affect the way young adults handle the transition to work and romantic relationships (Beyers \& Seiffge-Krenke, 2010). The current study examined how adolescent identification with school and friendships is associated with work and romantic relationships 5 years later in emerging adulthood. Also, the current study examined the associations among employment status and status of having a romantic relationship with identification with one's work or romantic relationship in emerging adulthood.

\section{Work and Romantic Relationships in Emerging Adulthood}

Social-structural changes in many industrialized Western nations have yielded a delay in role transitions into work and stable romantic relationships until the late teens and $20 \mathrm{~s}$ (Arnett, 2004). In the Netherlands, like in many western countries, emerging adults often are involved in postsecondary education and postpone their career and family formation. At the same time, many youths make transitions to part-time work and romantic relationships. According to the National Statistics

\footnotetext{
'Research Centre Adolescent Development, Utrecht University, Utrecht, the Netherlands

${ }^{2}$ Tilburg University, Tilburg, the Netherlands
}

\section{Corresponding Author:}

Susan Branje, PhD, Research Centre Adolescent Development, Utrecht University, PO BOX 80140, 3508TC Utrecht, the Netherlands.

Email: s.branje@uu.nl 
Netherlands (2012), $54.8 \%$ of the emerging adults (18-26 years of age) have found a job for at least $12 \mathrm{hr}$ a week. Romantic relationship status is common among emerging adults (Collins, Welsh, \& Furman, 2009). About $48 \%$ of the Dutch 18- to 20 -year-olds report being involved in a romantic relationship, and this percentage increases to $73 \%$ among 21- to 23 -yearolds (W. Meeus, Branje, \& Overbeek, 2004). These findings are comparable to the U.S. findings, showing that by 18 years of age, more than $70 \%$ of adolescents report having had a romantic relationship in the previous 18 months. As many emerging adults postpone these role transitions to work and family, it may not be surprising that job status was found to be unrelated to the likelihood of feeling adolescent or adult among emerging adults. However, being involved in a romantic relationship was positively related to emerging adults' subjective perceptions of adulthood (Reitzle, 2007), suggesting that the transition to romantic relationships still is an important step toward maturity.

The developmental tasks of becoming engaged in stable romantic relationships as well as in work are twofold. First, emerging adults need to make the transition to romantic relationship or work. Second, and more importantly, they need to develop the capacity to have high-quality romantic relationships (Collins et al., 2009), and to incorporate an adult career into their identity (Erikson, 1968). A major task facing emerging adults when they have found a job is to develop a high level of work role identification $(\mathrm{Ng} \&$ Feldman, 2007; Roisman, Masten, Coatsworth, \& Tellegen, 2004; Scandura, 2002). In emerging adulthood, work experiences become more focused on preparation for adult work roles. In exploring various work possibilities, emerging adults begin to consider how their work experiences will lay the basis for the jobs they might have through adulthood (Arnett, 2000; Skorikov \& Vondracek, 1997; Vondracek \& Skorikov, 1997). Similarly, when emerging adults enter a romantic relationship, they need to develop an idea of whether their partner is the person they want to spend their life with and possibly build a family with. Consequently, romantic relationship identity starts to become more salient during this period (Meeus, Branje, Van der Valk, \& De Wied, 2007). Research has shown that emerging adults who were involved in a long-term relationship were more likely to have an achieved or a moratorium identity and less likely to have a diffused identity in the area of balancing work and family, although no differences were found for relational identity (Frisén \& Wängqvist, 2011). In the current study, we will focus on both status of and identification with work and romantic relationships.

The identification with social roles such as relationships or work can be captured with identity formation processes, such as commitment and exploration (Klimstra et al., 2013; Marcia, 1966). In the current study, we differentiated between three processes of identity formation. Commitment refers to the identification with a certain option within a life domain. In-depth exploration refers to reflecting and gathering information on the merits of current commitments; and reconsideration reflects the reevaluation of current commitments and comparison with alternatives (Crocetti, Rubini, \& Meeus, 2008;
Luyckx, Goossens, \& Soenens, 2006). Despite the recognized importance of accomplishing the developmental tasks of becoming fully employed and establishing romantic relationships, our knowledge about precursors of accomplishing and identifying with these tasks remains incomplete. Also, information on how status of and identification with these tasks are related to each other in emerging adulthood is lacking (Beyers \& Seiffge-Krenke, 2010).

\section{Identity Formation in Adolescence and Work and Romantic Relationships in Emerging Adulthood}

Preparation for emerging adult role transitions starts during adolescence. For example, research has shown that adolescents' expectations regarding future career paths and identity affect their future fulfillment of these roles (Crockett \& Beal, 2012). Similarly, adolescents' ego development was found to affect their intimacy in romantic relationships in emerging adulthood (Beyers \& Seiffge-Krenke, 2010). Identity formation takes place in several domains across adolescence and emerging adulthood, including the relational and vocational domains (Erikson, 1950; Grotevant, 1987). Within the vocational domain, identity formation might start with commitment to and exploration of educational choices at school, and within the relational domain, identity formation regarding friendships might precede romantic identity. Accordingly, we hypothesized identity formation within the vocational or relational domain in adolescence to affect the timing of role transitions and identity formation within that domain in emerging adulthood. This hypothesis is further supported by the findings that the successful attainment of the developmental tasks of work and romantic relationships around age 30 is better predicted by more salient and already well-organized tasks of academic success and friendship during the early 20 s than by emerging developmental tasks like work and romantic relationships around age 20 (Roisman et al., 2004).

Friendship interactions can be considered as prototypes of interactions compatible with romantic relationships and can function as a testing ground for managing emotions in the context of voluntary close relationships (Connolly, Craig, Goldberg, \& Pepler, 2004; Feiring, 1996; McNelles \& Connolly, 1999). Hence, friendships are thought to contribute to the quality of later romantic relationships (Connolly \& Goldberg, 1999; Seiffge-Krenke, 2003; Shulman, Laursen, Kalman, \& Karpovsky, 1997). Considering identity formation, research confirmed these expected links between friendship and romantic relationships (De Goede, Branje, Van Duin, Van der Valk, \& Meeus, 2012; Meeus et al., 2007). Commitment to best friends in both adolescence and emerging adulthood was found to be significantly but weakly related to commitment to romantic partners 6 years later (Meeus et al., 2007). Also, base levels and developmental changes in commitment to friends across adolescence were positively associated with commitment to romantic partners in late adolescence (De Goede et al., 2012). The present study will extend these findings by examining whether friendship identity in terms of commitment, 
in-depth exploration, and reconsideration during adolescence is related to the status of and identification with a romantic relationship in emerging adulthood.

The school-to-work transition is an important task that emerging adults have to accomplish. How individuals identified themselves with their school and courses they attended might be of influence on how smoothly this transition occurs and on how individuals identify themselves with their work (Roisman et al., 2004). Research has shown that social and academic competencies during adolescence were important predictors of later success in the adult workplace (Roisman et al., 2004; Vaillant \& Vaillant, 1981). Moreover, overall career preparation in high school has been found to be associated with adjustment (Stringer, Kerpelman, \& Skorikov, 2012) and career development (Porfeli \& Skorikov, 2010; Skorikov, 2007) in emerging adulthood. The current study will extend these findings by examining whether school identity during adolescence is related to employment status and identification with this work in emerging adulthood.

\section{Associations Between Work and Romantic Relationships in Emerging Adulthood}

Romantic relationship status and employment status are two emerging developmental tasks during emerging adulthood that might influence each other. Role transitions are interdependent and might affect each other's timing and sequencing (Schoon, Martin, \& Ross, 2007) and requirements of one role might spill over to other roles. For example, when being involved in a romantic relationship and exploring the possibilities to form a stable family for the future, the pressure to acquire a stable income might increase. Likewise, being involved in a job might increase the wish for building a family life, starting with a stable romantic relationship. One previous study examining whether the likelihood of developmental transitions in 20- to 32 -year-olds was affected by other transitions found no significant effect of the transition to cohabitation or marriage on the transition to work. However, this study found that the transition to work predicted the transition to cohabitation and marriage (Masche, 2008). Thus, employment status might increase the likelihood of having a stable romantic relationship.

In terms of identity, emerging adults strive to find environments that are suitable for constellations of emerging role identities (Erikson, 1968). The interdependence of adult roles might mean that emerging adults' transition to a specific role might affect not only identification with the corresponding role but also identification with other roles. The fit between multiple adult roles and role identities determines the success of appropriately accomplishing the two important developmental tasks of becoming committed to work and romantic relationships (Erikson, 1968; Ng \& Feldman, 2007). Thus, emerging adults who are involved in both work and romantic relationships might be able to adapt more easily and more quickly to demanding environments and have higher levels of work and relational identification than emerging adults who are involved in only one of these roles.

\section{The Present Study}

In sum, the current study will examine the precursors of adolescent romantic relationship status and employment status, and identity in emerging adulthood, assessed 5 years later. We will also examine how employment status and romantic relationships are related to each other and to the identification with these adult roles during emerging adulthood at age 21 and 25:

Research Question 1: Is best friend identity in adolescence related to romantic relationship identity in emerging adulthood?

Research Question 2: Is school identity during adolescence related to work identity in emerging adulthood?

Research Question 3: How are romantic relationship status and employment status related to each other and to the identification with work and romantic relationships in emerging adulthood?

We will examine these research questions in a sample with two age cohorts of 16 and 20 at Time 1, using two measurement waves with 5 years in between. We will explore whether associations differ for late adolescents and emerging adults. These differences might be expected because at around age 20, work and romantic relationships are emerging domains that are less salient than at age 25 (Roisman et al., 2004). In these research questions, we will control for gender and educational level, because gender and educational level have been found to be related to the outcome variables (Frisén \& Wängqvist, 2011; Klimstra, Hale, Raaijmakers, Branje, \& Meeus, 2010; Schoon, 2010).

\section{Method}

\section{Participants}

Participants were 1,026 adolescents who participated in the fifth and sixth waves of the ongoing longitudinal study Conflict and Management of Relationships (CONAMORE; Meeus et al., 2006). The sample consisted of two age cohorts: a younger cohort ( $n=735 ; 72 \%)$, who were on average 16.44 (standard deviation $[S D]=0.88$ ) years old at the fifth wave of measurement, and an older cohort $(n=291 ; 28 \%)$, who were on average $20.53(S D=0.83)$ years old during the fifth measurement wave. The younger cohort consisted of 337 males $(46 \%)$ and 398 females (54\%), and the older cohort consisted of 119 males (41\%) and 172 females (59\%). Eighty-nine percent of the adolescents identified themselves as Dutch, and $11 \%$ indicated that they belonged to various ethnic minorities (e.g., Surinamese, Antillean, Moroccan, and Turkish).

We performed attrition analyses to examine whether the 1,026 respondents who participated in Wave 6 differed from the original CONAMORE sample of 1,313 participants. Males appeared to drop out significantly more compared to females, $\chi^{2}(1, N=1,312)=26.548, p<.001, \varphi=.141$. Also, participants were slightly younger than respondents who did not participate in Wave $6, t(1,308)=2.965, p=.003$. 
Concerning identity, people who participated in the sixth wave had significantly higher friend reconsideration, $t(331.400)=$ $-4.533, p<.001$, higher school reconsideration, $t(327.341)$ $=-4.508, p<.001$, and higher school exploration in depth, $t(1,194)=-2.483, p=.013$, than people who did not participate in the sixth wave.

\section{Procedure}

Participants were initially recruited from various high schools in the surroundings of Utrecht, the Netherlands. Participants and their parents received an invitation letter, describing the research project and goals, and explaining the possibility to decline from participation. More than $99 \%$ of the approached adolescents were willing to participate. Questionnaire completion took place at school after school hours or during home visits. The fifth measurement wave (Time 1 from now on) took place in 2005, the sixth wave (Time 2 from now on) took place 5 years later in 2010 . Trained assistants gave verbal instructions to participants in addition to written instructions in the questionnaires. Confidentiality of responses was guaranteed. Participants received $€ 10$ (which is approximately US\$13) at Time 1 and $€ 30$ (which is approximately US\$39) at Time 2 as a reward for their participation.

\section{Measures}

Employment Status. Participants who were involved in work at Time 2 received a score of 1 on the variable Employment status, and participants not involved in work received a score of 0 . A total of 435 participants (59\%) from the younger cohort and 232 participants $(80 \%)$ from the older cohort reported being involved in a job at Time 2. In all, $65 \%$ of the females and $65 \%$ of the males had a job. Of the participants that reported having a job at Time 2, several had a part-time job next to their education, especially in the younger cohort. In the younger cohort, $39 \%$ of participants had a job and followed education, $20 \%$ had a job only, $33 \%$ were following education only, and $8 \%$ had neither a job nor followed education. In the older cohort, $22 \%$ of participants had a job and followed education, $58 \%$ had a job only, $14 \%$ were following education only, and $6 \%$ had neither a job nor followed education.

Romantic Relationship Status. We coded romantic relationship status at Time 2 as 0 , no relationship, and 1, in a relationship. A total of 345 participants (47\%) from the younger cohort and 183 participants $(63 \%)$ from the older cohort reported being involved in a romantic relationship at Time 2 , and $60 \%$ of the females and $41 \%$ of the males reported having a romantic relationship. Whereas 377 participants were involved in both a job and a romantic relationship, 208 participants were neither involved in a job nor involved in a romantic relationship, 290 participants only had work, and 151 participants only had a romantic relationship.

Identity. The Utrecht-Management of Identity Commitments scale (Crocetti et al., 2008) was used to assess romantic relationship identity and work identity at Time 2 and friendship identity and school identity at Time 1 . This self-report measure includes three subscales: Commitment (5 items), in-depth exploration (5 items), and reconsideration (3 items). At Time 1, participants were asked to identify their best friend and fill out questionnaire about friendship identity while thinking about the relationship with this friend. We explicitly asked participants not to select a romantic partner as their best friend. We did not restrict participants to select a same-age, same-school, or same-gender friend. At Time 1, participants also answered the questions about their current education. At Time 2, participants filled out the questionnaire when they were involved in work or a romantic relationship. Sample items were "My partner/work/friend/education gives me certainty in life" for commitment, "I try to find out a lot about my partner/work/ friend/education" for in-depth exploration, and "I often think it would be better to try and find a different partner/work/ friend/education" for reconsideration. Participants responded on a 5-point Likert-type scale ranging from 1 (entirely correct) to 5 (not correct at all). Scale scores were recoded so that higher scores indicate more commitment, in-depth exploration, and reconsideration. Psychometric properties for this questionnaire are good (Crocetti et al., 2008). In the current study, reliability was high for commitment (i.e., Cronbach's $\alpha$ s ranged from .91 to .92), in-depth exploration (i.e., Cronbach's $\alpha$ s ranged from .77 to .88 ), and reconsideration (i.e., Cronbach's $\alpha$ s ranged from .90 to .94 ).

Educational Level. At Time 2, participants reported their highest degree and the type of education they were currently involved in. These two variables were combined to assess educational level. That is, when participants were no longer following education, we used their highest degree as an indicator of educational level. When participants were still following education, we used the level of their current study as an indicator of educational level. Educational level was coded from 1 (schools preparing for lower level tertiary education or lower level jobs) to 4 (university).

\section{Analytic Strategy}

We examined the research questions with multigroup multiple regression analyses in Mplus (Muthén \& Muthén, 1998-2007), with cohort as the grouping variable. To examine the effects of school identity and relationship status on employment status as well as the effects of friendship identity and employment status on relationship status, we used probit regressions in Mplus, using weighted least squares estimation with missing data. Probit regression is the default in Mplus to model dichotomous or binary outcome variables (Muthén, du Toit, \& Spicis, 1997). In the probit model, the inverse standard normal distribution of the probability is modeled as a linear combination of the predictors. The probit regression coefficients give the change in the $z$ score for a one-unit change in the predictor.

To examine the effects of school identity and romantic relationship status on work identity as well as the effects of 
Table I. Means of the Study Variables.

\begin{tabular}{|c|c|c|c|c|c|c|}
\hline & T2 Work & T2 No Work & $F$ Value & T2 Relationship & T2 No Relationship & $F$ Value \\
\hline TI School exploration & 3.256 & 3.205 & 1.026 & 3.280 & 3.193 & 3.184 \\
\hline TI Friend commitment & 3.658 & 3.623 & 0.552 & 3.688 & 3.601 & 3.682 \\
\hline TI Friend exploration & 3.244 & 3.186 & $\mathrm{I} .484$ & 3.291 & 3.151 & $9.769 * *$ \\
\hline TI Friend reconsideration & 1.599 & 1.705 & $4.576 *$ & 1.579 & 1.698 & $6.294 *$ \\
\hline T2 Work reconsideration & 2.486 & - & - & 2.461 & 2.519 & 0.444 \\
\hline T2 Relational commitment & 4.239 & 4.076 & $7.617^{* *}$ & 4.191 & - & - \\
\hline T2 Relational exploration & 3.900 & 3.914 & 0.057 & 3.896 & - & - \\
\hline T2 Relational reconsideration & 1.430 & 1.534 & 2.235 & 1.465 & - & - \\
\hline
\end{tabular}

Note. ${ }_{p} p<.05 . * * p<.01 . * * p p<.001$.

Table 2. Correlations Among the Study Variables.

\begin{tabular}{|c|c|c|c|c|c|}
\hline & I & 2 & 3 & 4 & 5 \\
\hline \multicolumn{6}{|l|}{ I. TI School commitment } \\
\hline 2. TI School exploration & $.386 * * *$ & & & & \\
\hline 4. T2 Work commitment & $.120 * *$ & $.213 * * *$ & .019 & & \\
\hline 5. T2 Work exploration & $.093^{*}$ & $.311 * * *$ & $.104 * *$ & $.649 * * *$ & \\
\hline 6. T2 Work reconsideration & -.063 & -.035 & $.134 * *$ & $-.409 * * *$ & $-.256 * * *$ \\
\hline \multicolumn{6}{|l|}{ I. TI Friend commitment } \\
\hline 2. TI Friend exploration & $.455^{* * *}$ & & & & \\
\hline 3. TI Friend reconsideration & $-.300 * * *$ & -.039 & & & \\
\hline 4. T2 Relational commitment & $.215^{* * * *}$ & $.105^{*}$ & $-.173 * * *$ & & \\
\hline 5. T2 Relational exploration & $.169 * * *$ & $.354 * * *$ & -.076 & $.404 * * *$ & \\
\hline
\end{tabular}

Note. $*_{p}<.05 . * * p<.01 . * * * p<.001$.

friendship identity and employment status on relational identity, we used regression analyses in Mplus, using maximum likelihood estimation. These analyses could be performed only for cases that were involved in work or a romantic relationship.

In all analyses, we controlled for effects of gender and educational level on the outcome variable, as these variables have been found to affect transitions into and identification with work and relationships. We used Wald's tests to test whether coefficients differed for the younger and older cohorts. We evaluated model fit by the comparative fit index (CFI), with values above .95 indicating a good fit, and the root mean square error of approximation (RMSEA), with values up to .05 representing good fit and values up to .08 representing adequate model fit (Hu \& Bentler, 1999).

\section{Results}

\section{Descriptive Statistics and Correlations}

Table 1 shows the means and SDs of the identity measures. Multivariate analyses of variances revealed that emerging adults involved in work at Time 2 significantly differed from emerging adults not involved in work in relationship identity at Time $2, F(3,519)=3.316, p=.020$, but did not differ in school identity at Time $1, F(3,955)=.918, p=.432$, or friendship identity at Time $1, F(3,984)=2.032, p=.108$. Emerging adults involved in work at Time 2 reported significantly lower friendship reconsideration at Time 1 and significantly higher relational commitment at Time 2 than emerging adults not involved in work. Furthermore, emerging adults involved in a romantic relationship at Time 2 significantly differed from emerging adults not involved in a romantic relationship in work identity at Time $2, F(3,651)=3.258, p=.021$, and friendship identity at Time $1, F(3,984)=5.201, p=.001$, but did not differ in school identity at Time $1, F(3,955)=2.090, p=.100$. Emerging adults involved in a romantic relationship at Time 2 reported significantly higher friendship exploration and lower friendship reconsideration at Time 1 and significantly higher work commitment and exploration at Time 2 than emerging adults not involved in a romantic relationship.

Table 2 shows the correlations among the study variables. Within all domains, commitment was significantly and 
Table 3. Probit Regression Analyses of Employment Status and Romantic Relationship Status in Emerging Adulthood.

\begin{tabular}{|c|c|c|c|c|}
\hline & \multicolumn{4}{|c|}{ T2 Employment Status } \\
\hline & \multicolumn{4}{|c|}{ Cohort } \\
\hline & \multicolumn{2}{|c|}{ Young } & \multicolumn{2}{|c|}{ Old } \\
\hline & $z$ & SE & $z$ & SE \\
\hline Gender & -.068 & .092 & .068 & .092 \\
\hline Educational level & $-.262^{* * *}$ & .041 & $-.262 * * *$ & .041 \\
\hline TI School commitment & .110 & .076 & .110 & .076 \\
\hline TI School exploration & -.066 & .066 & -.066 & .066 \\
\hline TI School reconsideration & -.007 & .059 & -.007 & .059 \\
\hline \multirow[t]{5}{*}{ T2 Relationship status } & $.190 *$ & .093 & $.190 *$ & .093 \\
\hline & \multicolumn{4}{|c|}{ T2 Relationship Status } \\
\hline & \multicolumn{4}{|c|}{ Cohort } \\
\hline & \multicolumn{2}{|c|}{ Young } & \multicolumn{2}{|c|}{ Old } \\
\hline & $z$ & SE & $z$ & SE \\
\hline Gender & $.579 * * *$ & .100 & .157 & .162 \\
\hline Educational level & -.066 & .037 & -.066 & .037 \\
\hline TI Friend commitment & .015 & .070 & .015 & .070 \\
\hline TI Friend exploration & .085 & .067 & .085 & .067 \\
\hline TI Friend reconsideration & -.061 & .060 & -.061 & .060 \\
\hline T2 Employment status & $.25 I^{* *}$ & .092 & $.25 \mathrm{I} * *$ & .092 \\
\hline
\end{tabular}

Note. $S E=$ standard error.

$* p<.05 . *_{p}<.01$. $* * * p<.001$.

positively related to in-depth exploration and significantly negatively related to reconsideration. Correlations between in-depth exploration and reconsideration had a weaker effect size and were not consistently significant for all domains.

\section{Predicting Employment Status in Emerging Adulthood}

To predict employment status in emerging adulthood, we used multigroup probit regression to regress employment status at Time 2 on gender, educational level, school identity at Time 1 and romantic relationship status at Time 2. We used Wald's tests for each group of predictors to test whether the effects differed for the two age cohorts. Effects of gender $\left(\Delta \chi^{2}=\right.$ $.400, \Delta d f=1, p=.527)$, educational level $\left(\Delta \chi^{2}=1.504, \Delta d f\right.$ $=1, p=.220)$, school identity $\left(\Delta \chi^{2}=3.515, \Delta d f=3, p=\right.$ $.319)$, and romantic relationship status $\left(\Delta \chi^{2}=.220, \Delta d f=1\right.$, $p=.639)$ did not differ across cohorts. Fit of the final model was good, with $\chi^{2}=6.209, d f=6, p=.400$, RMSEA $=$ .009 , and CFI $=.995$.

Results (see Table 3, upper panel) showed that educational level significantly predicted employment status in emerging adulthood. Emerging adults with higher educational levels were less likely to be involved in work. Also, romantic relationship status significantly predicted employment status. Emerging adults involved in a romantic relationship were more likely to have a job. No other effects were significant. Thus, results suggest that the transition to romantic relationships during emerging adulthood goes together with the transition to work but is not predicted by identity formation in the friendship domain during adolescence.

\section{Predicting Romantic Relationship Status in Emerging Adulthood}

To predict romantic relationship status in emerging adulthood, we used multigroup probit regression to regress romantic relationship status at Time 2 on gender, educational level, and friendship identity at Time 1 and employment status at Time 2. Effects of educational level $\left(\Delta \chi^{2}=.057, \Delta d f=1, p=.812\right)$, employment status $\left(\Delta \chi^{2}=.180, \Delta d f=1, p=.671\right)$, and friendship identity $\left(\Delta \chi^{2}=1.947, \Delta d f=3, p=.583\right)$ did not differ across the two cohorts, but effects of gender $\left(\Delta \chi^{2}=5.339\right.$, $\Delta d f=1, p=.021)$ differed significantly across cohorts. Fit of the final model was good, with $\chi^{2}=2.088, d f=5$, $p=.837$, RMSEA $=.000$, and CFI $=1.000$.

Results (see Table 3, lower panel) showed that gender was significantly associated with romantic relationship status in emerging adulthood but only for the younger cohort. In the younger cohort, females were more likely to be involved in a romantic relationship than males. Moreover, employment status at Time 2 was significantly associated with romantic relationship status. Emerging adults who were involved in work were more likely to be involved in a romantic relationship than emerging adults who were not involved in work. No other effects were significant. Thus, results suggest that the transition to work during emerging adulthood in different domains goes together with the transition to romantic relationship status but is not predicted by identity formation in the school domain during adolescence.

\section{Predicting Work Identity in Emerging Adulthood}

To predict work identity in emerging adulthood, we used a multigroup regression analysis to regress work identity at Time 2 on gender, educational level, school identity at Time 1 and romantic relationship status at Time 2. Effects of gender $\left(\Delta \chi^{2}=6.028, \Delta d f=3, p=.110\right)$, and romantic relationship status $\left(\Delta \chi^{2}=1.110, \Delta d f=3, p=.775\right)$ did not differ across cohorts, but effects of educational level $\left(\Delta \chi^{2}=5.095\right.$, $\Delta d f=3, p=.165)$ and school identity differed significantly $\left(\Delta \chi^{2}=22.020, \Delta d f=9, p=.009\right)$. Fit of the final model was good, with $\chi^{2}=11.907, d f=9, p=.219$, RMSEA $=.033$, and $\mathrm{CFI}=.995$.

Results (see Table 4, upper panel) showed that educational level was significantly associated with work commitment and exploration in emerging adulthood. Emerging adults with higher educational levels were less committed to their work and explored their work less. Moreover, for emerging adults of the older cohort, the three aspects of school identity were significantly associated with the same dimension of work identity. School commitment was positively associated with work commitment, school exploration was positively associated with work exploration, and school reconsideration was positively 
Table 4. Regression Analyses of Work and Romantic Relationship Identity in Emerging Adulthood.

\begin{tabular}{|c|c|c|c|c|c|c|c|c|c|c|c|c|}
\hline & \multicolumn{4}{|c|}{$\frac{\text { T2 Work Commitment }}{\text { Cohort }}$} & \multicolumn{4}{|c|}{ T2 Work Exploration in Depth } & \multicolumn{4}{|c|}{ T2 Work Reconsideration } \\
\hline & $\beta$ & SE & $\beta$ & SE & $\beta$ & SE & $\beta$ & SE & $\beta$ & SE & $\beta$ & $S E$ \\
\hline Gender & -.027 & .036 & .032 & .043 & -.043 & .034 & -.056 & .045 & .062 & .043 & .055 & .038 \\
\hline TI School exploration & $.218^{* * *}$ & .051 & -.056 & .072 & $.27 \mathrm{I} * * *$ & .050 & $.269 * * *$ & .070 & -.089 & .057 & .030 & .076 \\
\hline TI School reconsideration & .068 & .052 & -.008 & .072 & $.140 * *$ & .051 & .072 & .072 & .096 & .056 & $.160 *$ & .076 \\
\hline \multirow[t]{4}{*}{ T2 Relationship status } & .050 & .036 & .058 & .042 & $.079 *$ & .035 & $.100 *$ & .044 & -.049 & .044 & -.042 & .037 \\
\hline & \multicolumn{4}{|c|}{ T2 Relational Commitment } & \multicolumn{4}{|c|}{ T2 Relational Exploration in Depth } & \multicolumn{4}{|c|}{ T2 Relational Reconsideration } \\
\hline & \multicolumn{2}{|c|}{ Young } & \multicolumn{2}{|c|}{ Old } & \multicolumn{2}{|c|}{ Young } & \multicolumn{2}{|c|}{ Old } & \multicolumn{2}{|c|}{ Young } & \multicolumn{2}{|c|}{ Old } \\
\hline & $\beta$ & $S E$ & $\beta$ & $S E$ & $\beta$ & $S E$ & $\beta$ & SE & $\beta$ & SE & $\beta$ & SE \\
\hline Gender & .043 & .042 & .051 & .050 & .028 & .040 & .032 & .047 & $-.134 * *$ & .042 & $-.153 * *$ & .050 \\
\hline Educational level & -.063 & .044 & -.063 & .045 & -.044 & .042 & -.044 & .042 & .001 & .045 & .001 & .044 \\
\hline TI Friend commitment & $.177^{* *}$ & .062 & .058 & .088 & -.097 & .060 & $.172 *$ & .083 & .070 & .064 & .048 & .086 \\
\hline TI Friend exploration & .020 & .060 & .082 & .082 & $.398 * * *$ & .054 & $.291 * * *$ & .075 & -.083 & .061 & .111 & .080 \\
\hline TI Friend reconsideration & -.106 & .056 & -.117 & .081 & $-.108^{*}$ & .054 & .021 & .077 & .098 & .057 & $.221 * *$ & .077 \\
\hline T2 Employment status & $.112^{*}$ & .045 & $.099 *$ & .041 & .021 & .043 & .018 & .038 & -.077 & .046 & -.066 & .040 \\
\hline
\end{tabular}

Note. $* p<.05 . * * p<.01 . * * p<.001$.

associated with work reconsideration. For emerging adults in the younger cohort, school exploration was positively associated not only with work exploration but also with work commitment, and school reconsideration was positively associated with work exploration. Also, romantic relationship status was significantly related to work exploration: Emerging adults who were involved in a romantic relationship explored their work more. No other effects were significant. Thus, results showed that work identity in emerging adulthood is positively predicted by school identity in adolescence, especially in the older cohort, and by romantic relationship status in emerging adulthood.

\section{Predicting Romantic Identity in Emerging Adulthood}

To predict romantic identity in emerging adulthood, we used a multigroup regression analysis to regress romantic identity at Time 2 on gender, educational level, and friendship identity at Time 1 and employment status at Time 2. Effects of gender $\left(\Delta \chi^{2}=4.788, d f=3, p=.188\right)$, educational level $\left(\Delta \chi^{2}=2.991, d f=3, p=.393\right)$, and employment status $\left(\Delta \chi^{2}=2.091, d f=3, p=.554\right)$ did not differ across the two age cohorts, but effects of friendship identity differed significantly $\left(\Delta \chi^{2}=22.616, d f=9, p=.007\right)$. Fit of the final model was good, with $\chi^{2}=9.428, d f=9, p=.399$, RMSEA $=.014$, and CFI $=.999$.

Results (see Table 4, lower panel) showed that gender was significantly associated with relational reconsideration in emerging adulthood. Females were less likely to reconsider their romantic relationship than males. Also, for emerging adults of the older cohort, friendship commitment and exploration at Time 1 were significantly and positively associated with romantic exploration at Time 2 , and friendship reconsideration at Time 1 was significantly and positively associated with romantic reconsideration at Time 2. For emerging adults in the younger cohort, friendship commitment was positively associated with romantic commitment, friendship exploration was positively associated with romantic exploration, and friendship reconsideration was negatively associated with romantic exploration. Moreover, employment status at Time 2 significantly predicted relational commitment for both cohorts. Emerging adults who were involved in work were more committed to their romantic relationship than emerging adults who were not involved in work. No other effects were significant. Thus, results showed that relational identity in emerging adulthood is positively predicted by friendship identity in adolescence and by employment status in emerging adulthood.

\section{Discussion}

The goal of the present study was to examine whether status of and identification with work and romantic relationships in emerging adulthood were related to each other and to school and friendship identity in adolescence. The use of a longitudinal design, spanning a period of 5 years from late adolescence to emerging adulthood, enabled us to examine the effects of 
earlier identity in the related domain of school or friendships on status of and identification with work and romantic relationships, respectively. Results showed that employment status and romantic relationship status were significantly related to each other. Employment status was also significantly related to relational identity, and romantic relationship status was significantly related to identification with work, but in different ways. Moreover, identification with work and romantic relationships, but not employment status and romantic relationship status, could be predicted by identity formation processes in the related domains of school and friendships in adolescence.

As expected, employment status and romantic relationship status were significantly related to each other. Emerging adults who were involved in work were also more likely to be involved in a romantic relationship. This finding is in line with the view that role transitions go hand in hand and reinforce each other (Arnett, 1998, 2000; Elder, 1998; Schoon et al., 2007). The transition to a serious romantic relationship involves obligations to a significant other, and both emerging adults and their partner might have expectations regarding the fulfillment of these obligations. One of these obligations is to take care of each other and provide a stable base of living. Having a job might thus become more salient when one is involved in a romantic relationship. Similarly, when emerging adults enter the workforce, the need to establish a stable relationship that eventually forms the base for family life might become more urgent.

Strikingly, employment status was significantly related to relational identity and romantic relationship status was significantly related to work identity for both age cohorts, but the nature of these associations differed. Whereas employment status was significantly related to stronger commitment to romantic partners, romantic relationship status was significantly related to in-depth exploration of work. The finding that employment status predicted stronger commitment to romantic partners suggests that the entrance into the labor market increases the saliency of romantic relationships for emerging adults. When emerging adults are not involved in work, they might engage in romantic relationships in a more exploratory way, in line with the prolonged period of exploration that characterizes emerging adulthood in modern industrialized societies (Arnett, 2000). However, when emerging adults are involved in work, their view on their romantic relationship might change in favor of a more long-term perspective toward family formation, reflected in higher commitment to their partner. Similarly, the finding that romantic relationship status was significantly related to in-depth exploration of work suggests that the transition to romantic relationship triggers the need to acquire a career and a stable income instead of just a job. Together, these findings confirm the interdependence of adult roles and suggest that emerging adults are better able to integrate new roles into their identity when they made the transition to multiple interdependent roles than when they only made the transition to the corresponding role (Erikson, 1968; Ng \& Feldman, 2007).

Identity formation processes in adolescence in the related domains of school and friendships were significantly related to work identity and relational identity in emerging adulthood 5 years later but were not significantly related to work and romantic relationship status. Apparently, adolescent identity is only related to the identification with adult roles in related domains and not with the transition to these roles itself. Although theory suggests that the accomplishment of adult roles in the relational and vocational domain already starts in adolescence with friendship identity and school identity (Erikson, 1950; Grotevant, 1987; Roisman et al., 2004), the transition into these adult roles may be affected by other factors such as educational level and family background (Oesterle, Hawkins, Hill, \& Bailey, 2010). When the transition into these roles has been made, identity formation within the vocational or relational domain in adolescence does affect identity formation within the corresponding domain in emerging adulthood. Friendship identity was found to predict romantic relationship identity, and school identity was found to predict work identity over a period of 5 years. These findings confirm the notion that friendships serve as prototypes of interactions compatible with romantic relationships (Connolly et al., 2004; Feiring, 1996; McNelles \& Connolly, 1999) and contribute to the quality of later romantic relationships (Connolly \& Goldberg, 1999; Seiffge-Krenke, 2003; Shulman et al., 1997). Also, these findings are in line with research showing that academic competencies and career preparation during adolescence are important predictors of success in the adult workplace (Roisman et al., 2004; Vaillant \& Vaillant, 1981) and career development (Porfeli \& Skorikov, 2010; Skorikov, 2007) in emerging adulthood.

Spillover of earlier school identity to work identity in emerging adulthood was found most consistently for similar processes, that is, school or friend commitment spilled over to work or relational commitment, school or friend exploration spilled over to work or relational exploration, and school or friend reconsideration spilled over to work or relational reconsideration. This was particularly true for emerging adults of the older cohort, for whom the three aspects of school and friend identity were significantly associated with the same dimension of work and relational identity 5 of the 6 times. Emerging adults who perceived that their education gave them security in live also feel that their job offers them security, emerging adults who reflect much upon the merits of their education also reflect more on the merits of their job, and emerging adults who consider changing from educational program more also consider changing jobs more.

For emerging adults in the younger cohort, in particular indepth exploration of work and romantic relationships was related to identity processes in the domain of school and friendships 5 years earlier. These findings might be explained by changes in the saliency of work and romantic relationships between age 20 and 25 (Roisman et al., 2004): For the older cohort, work and romantic relationships might be more salient and well-organized tasks than for the younger cohort. Relationship status may be more salient at age 25 than at age 20, when the task of building intimate partner relationships is just emerging. Similarly, employment status at the early ages of emerging adulthood might mainly involve temporary jobs after 
the first entrance into the work space, whereas employment status by age 25 might comprise more serious jobs that are more closely linked to adult work roles (Groot \& Verberne, 1997) and corresponding identity processes in related domains earlier in life. In-depth exploration might be more typical or normative for emerging developmental tasks than commitment and reconsideration. At age 20, emerging adults may reflect and gather information on their job or relationship but are not yet as committed to these emerging domains as they typically are or reevaluate as they typically do. In-depth exploration around age 25 may therefore be better explained by earlier identity processes than in-depth exploration around age 20. This proposition is strengthened by the unexpected positive association of school reconsideration with work exploration in the younger cohort, suggesting that adolescents who have doubts about their education are more inclined to explore their job.

In our analyses, we controlled for gender and educational level. As expected, and in line with other studies (Crockett \& Beal, 2012; Klimstra et al., 2013), females were significantly more likely to be involved in a romantic relationship but only in the early stages at age 20 . Females were also less likely to reconsider their romantic relationship than males in both age cohorts. Educational level significantly predicted employment status in emerging adulthood. Emerging adults with higher educational levels were less likely to be involved in work. Emerging adults with higher educational levels were also less committed to their work and explored their work less. These findings are in agreement with the idea that extended schooling plays a major role in the delay of transitions to work and romantic relationships (Arnett, 2000).

\section{Strengths, Limitations, and Conclusion}

Important strengths of our study were the large sample size and the longitudinal design, which allowed us to examine the effects of identity in the domain of school and friendship on the status of and identification with work and romantic relationships.

There are also limitations that need to be discussed. A clear limitation of our study is the use of self-reports only to assess identity processes. Perceptions are to a large extent in the eye of the beholder (Branje, Van Aken, \& Van Lieshout, 2002), and our results could in part be explained by reporter bias. In addition, the adolescent identity factors used to predict identity in emerging adulthood stem from the same instrument, so associations might in part be the result of shared method variance. Another limitation is the focus on a normal population, and future studies should address whether our findings replicate in emerging adults with more problematic educational and relational histories. Moreover, although our study had a longitudinal design, spanning a period of 5 years, we cannot draw conclusions regarding direction of effects, as third variables might explain the associations. Also, only those participants who worked or had a romantic relationship filled out the work or relational identity measure, respectively, so we could not examine how work identity affects relational identity and vice versa for emerging adults without a job or a romantic relationship. Future research should look into more detail into the identity processes of individuals not having a job or romantic relationship.

In conclusion, the results of the present study indicate that employment status and romantic relationships are significantly related to each other, confirming that transitions to adult roles in different domains are interdependent. This interdependence of adult roles was further validated by the finding that employment status was significantly related to relational identity, and romantic relationship status was significantly related to identification with work. This suggest that emerging adults are better able to integrate their work or romantic relationship roles into their identity when they made the transition to both of these roles than when they only made the transition to one of these roles. Moreover, our findings that identification with work and romantic relationships, but not employment status and romantic relationship status, was predicted by identity formation processes in the related domains of school and friendships in adolescence, partly confirm that the accomplishment of adult roles in the relational and vocational domain already starts in adolescence. Overall, these results confirm the interdependence of role transitions in emerging adulthood and suggest that the base of the successful attainment of these transitions is laid in adolescence.

\section{Declaration of Conflicting Interests}

The authors declared no potential conflicts of interest with respect to the research, authorship, and/or publication of this article.

\section{Funding}

The author(s) disclosed receipt of the following financial support for the research, authorship, and/or publication of this article: The present study was supported by grants of The Netherlands Organisation for Scientific Research (NWO).

\section{References}

Arnett, J. J. (1998). Learning to stand alone: The contemporary American transition to adulthood in cultural and historical context. Human Development, 41, 295-315. doi:10.1159/000022591

Arnett, J. J. (2000). Emerging adulthood: A theory of development from the late teens through the twenties. American Psychologist, 55, 469-480. doi:10.1037//0003-066X.55.5.469

Arnett, J. J. (2004). Emerging adulthood: The winding road from the late teens through the twenties. New York, NY: Oxford University Press.

Beyers, W., \& Seiffge-Krenke, I. (2010). Does identity precede intimacy? Testing Erikson's theory on romantic development in emerging adults of the 21st century. Journal of Adolescent Research, 25, 387-415. doi:10.1177/0743558410361370

Branje, S. J. T., Van Aken, M. A. G., \& Van Lieshout, C. F. M. (2002). Relational support in families with adolescents. Journal of Family Psychology, 16, 351-362. doi:10.1037//0893-3200.16.3.351

Collins, W. A., Welsh, D. P., \& Furman, W. (2009). Adolescent romantic relationships. Annual Review of Psychology, 60, 631-652. doi:10.1146/annurev.psych.60.110707.163459 
Connolly, J. A., Craig, W., Goldberg, A., \& Pepler, D. (2004). Mixedgender groups, dating, and romantic relationships in early adolescence. Journal of Research on Adolescence, 14, 185-207. doi:10. 1111/j.1532-7795.2004.01402003.x

Connolly, J. A., \& Goldberg, A. (1999). Romantic relationships in adolescence: The role of friends and peers in their emergence and development. In W. Furman, B. B. Brown \& C. Feiring (Eds.), The development of romantic relationships in adolescence (pp. 266-290). New York, NY: Cambridge University Press.

Crocetti, E., Rubini, M., \& Meeus, W. H. J. (2008). Capturing the dynamics of identity formation in various ethnic groups: Development and validation of a three-dimensional model. Journal of Adolescence, 31, 207-222. doi:10.1016/j.adolescence.2007.09.002

Crockett, L. J., \& Beal, S. J. (2012). The life course in the making: Gender and the development of adolescents' expected timing of adult role transitions. Developmental Psychology, 48, 1727-1738. doi:10.1037/a0027538

De Goede, I. H. A., Branje, S., Van Duin, J., van der Valk, I. E., \& Meeus, W. (2012). Romantic relationship commitment and its linkages with commitment to parents and friends during adolescence. Social Development, 21, 425-442. doi:10.1111/j.1467-9507.2011. 00633.x

Elder, G. H., Jr. (1998). The life course as developmental theory. Child Development, 69, 1-12. doi:10.1111/j.1467-8624.1998.tb06128.x

Erikson, E. H. (1950). Childhood and society. New York, NY: Norton.

Erikson, E. H. (1968). Identity: Youth and crisis. New York, NY: Norton.

Feiring, C. (1996). Concepts of romance in 15-year-old adolescents. Journal of Research on Adolescence, 6, 181-200.

Frisén, A., \& Wängqvist, M. (2011). Emerging adults in Sweden: Identity formation in the light of love, work and family. Journal of Adolescent Research, 26, 200-221. doi:10.1177/0743558410376829

Groot, W., \& Verberne, M. (1997). Aging, job mobility, and compensation. Oxford Economic Papers, 49, 380-403. doi:10.1093/ oxfordjournals.oep.a028615

Grotevant, H. D. (1987). Toward a process model of identity formation. Journal of Adolescent Research, 2, 203-222. doi:10.1177/ 074355488723003

Havighurst, R. J. (1972). Developmental tasks and education (3rd ed.). New York, NY: McKay.

Hu, L., \& Bentler, P. M. (1999). Cutoff criteria for fit indexes in covariance structure analysis: Conventional criteria versus new alternatives. Structural Equation Modeling, 6, 1-55. doi:10.1080/ 10705519909540118

Klimstra, T., Hale, W. W. III, Raaijmakers, Q. A. W., Branje, S., \& Meeus, W. (2010). Identity formation in adolescence: Change or stability? Journal of Youth and Adolescence, 39, 150-162. doi: 10.1007/s10964-009-9401-4

Klimstra, T. A., Luyckx, K., Branje, S., Teppers, E., Goossens, L., \& Meeus, W. (2013). Personality traits, interpersonal identity, and relationship stability: Longitudinal linkages in late adolescence and young adulthood. Journal of Youth and Adolescence, 42, 1661-1673.

Luyckx, K., Goossens, L., \& Soenens, B. (2006). A developmentalcontextual perspective on entity construction in emerging adulthood: Change dynamics in commitment formation and commitment evaluation. Developmental Psychology, 42, 366-380. doi:10.1037/0012-1649.42.2.366

Marcia, J. E. (1966). Development and validation of ego-identity status. Journal of Personality and Social Psychology, 3, 551-558. doi:10.1037/h0023281

Marini, M. M. (1985). Determinants of the timing of adult role entry. Social Science Research, 14, 309-350. doi:10.1016/0049089X(85)90015-8

Masche, J. G. (2008). Reciprocal influences between developmental transitions and parent-child relationships in young adulthood. International Journal of Behavioral Development, 32, 401-411. doi:10.1177/0165025408093658

McNelles, L., \& Connolly, J. (1999). Intimacy between adolescent friends: Age and gender differences in shared affect and behavioral form. Journal of Research on Adolescence, 9, 143-159.

Meeus, W., Branje, S. J. T., \& Overbeek, G. J. (2004). Parents and partners in crime: A six year longitudinal study on changes in supportive relationships and delinquency in adolescence and young adulthood. Journal of Child Psychology and Psychiatry and Allied Disciplines, 45, 1288-1298. doi:10.1111/j.1469-7610.2004.00312.x

Meeus, W. H. J., Akse, J., Branje, S. J. T., Ter Bogt, T. F. M., Crommelin, P. M., Delsing, M. J. M. H., ... Spruijt, E. (2006). Codebook of the research project CONflict And Management Of RElationships (CONAMORE). Unpublished manuscript, Utrecht University, Utrecht, the Netherlands.

Meeus, W. H. J., Branje, S. J. T., Van der Valk, I., \& De Wied, M. (2007). Relationships with intimate partner, best friend, and parents in adolescence and early adulthood: A study of the saliency of the intimate partnership. International Journal of Behavioral Development, 31, 569-580. doi:10.1177/0165025407080584

Muthén, B. O., Du Toit, S. H. C., \& Spisic, D. (1997). Robust inference using weighted least squares and quadratic estimating equations in latent variable modeling with categorical and continuous outcomes. Unpublished paper.

Muthén, L., \& Muthén, B. (1998-2007). Mplus user's guide (4th ed.). Los Angeles, CA: Author.

Ng, T. W. H., \& Feldman, D. C. (2007). A school-to-work transition: A role identity perspective. Journal of Vocational Behavior, 17, 114-134. doi:10.1016/j.jvb.2007.04.004

Oesterle, S., Hawkins, J. D., Hill, K. G., \& Bailey, J. A. (2010). Men's and women's pathways to adulthood and their adolescent precursors. Journal of Marriage and Family, 72, 1436-1453. doi:10. 1111/j.1741-3737.2010.00775.x

Porfeli, E. J., \& Skorikov, V. B. (2010). Specific and diversive career exploration during late adolescence. Journal of Career Assessment, 18, 46-58. doi:10.1177/1069072709340528

Reitzle, M. (2007). The effects of work- and family-related transitions on young people's perception of being adult. Journal of Vocational Behavior, 70, 25-41. doi:10.1016/j.jvb.2006.04.002

Roisman, G. I., Masten, A. S., Coatsworth, J. D., \& Tellegen, A. (2004). Salient and emerging developmental tasks in the transition to adulthood. Child Development, 75, 123-133. doi:10.1111/j. 1467-8624.2004.00658.x

Scandura, T. A. (2002). The establishment years: A dependence perspective. In D. C. Feldman (Ed.), Work careers: A developmental perspective (pp. 159-185). San Francisco, CA: Jossey-Bass. 
Schoon, I. (2010). Becoming adult: The persisting importance of class and gender. In J. Scott, R. Crompton \& C. Lyonette (Eds.), Gender inequalities in the 21st century (pp. 19-39). Cheltenham, England: Edward Elgar.

Schoon, I., Martin, P., \& Ross, A. (2007). Career transitions in times of social change. His and her story. Journal of Vocational Behavior, 70, 78-96. doi:10.1016/j.jvb.2006.04.009

Schulenberg, J. E., Bryant, A. L., \& O’Malley, P. M. (2004). Taking hold of some kind of life: How developmental tasks relate to trajectories of well-being during the transition to adulthood. Development and Psychopathology, 16, 1119-1140. doi:10.1017/S0954579404040167

Seiffge-Krenke, I. (2003). Testing theories of romantic development from adolescence to young adulthood: Evidence of a developmental sequence. International Journal of Behavioral Development, 27, 519-531. doi:10.1080/01650250344000145

Shulman, S., Laursen, B., Kalman, Z., \& Karpovsky, S. (1997). Adolescent intimacy: Revisited. Journal of Youth and Adolescence, 26, 597-617. doi:10.1023/A:1024586006966

Skorikov, V. B. (2007). Continuity in adolescent career preparation and its effects on adjustment. Journal of Vocational Behavior, 70, 8-24. doi:10.1016/j.jvb.2006.04.007

Skorikov, V. B., \& Vondracek, F. W. (1997). Longitudinal relationships between part-time work and career development in adolescents. The Career Development Quarterly, 45, 221-235. doi:10. 1002/j.2161-0045.1997.tb00466.x

Statistics Netherlands. (2012). Statistical yearbook 2012. The Hague, the Netherlands: Author.

Stringer, K., Kerpelman, J., \& Skorikov, V. B. (2012). A longitudinal examination of career preparation and adjustment during the transition from high school. Developmental Psychology, 48, 1343-1354. doi:10.1037/a0027296

Vaillant, G. E., \& Vaillant, C. O. (1981). Natural history of male psychological health, X: Work as a predictor of positive mental health. American Journal of Psychiatry, 138, 1433-1440.

Vondracek, F. V., \& Skorikov, V. B. (1997). Leisure, school, and work activity preferences and their role in vocational identity development. The Career Development Quarterly, 45, 322-340. doi:10.1002/j.2161-0045.1997.tb00537.x

\section{Author Biographies}

Susan Branje is Professor of Adolescent Development at the Research Centre Adolescent Development, Utrecht University She received her PhD in 2003 at the Radboud University Nijmegen. Her work focuses on understanding the developmental changes in adolescents' personal relationships and the associations with development of individual characteristics and psychosocial adjustment.

Lydia Laninga-Wijnen completed two masters at Utrecht University (Research master Development and Socialization in Childhood and Adolescence, and Orthopedagogics). Currently she is a PhD student at Utrecht University, examining the composition of adolescent social relational networks and how adolescents within these networks mutually influence each other's positive behavior.

Rongqin Yu received her MSc degree in Psychopathology with honour at Maastricht University, the Netherlands. She is currently a $\mathrm{PhD}$ candidate in Research Center Adolescent Development, Utrecht University. Her current research focuses on the link between youths' personality and developmental outcomes in the context of peer relationships (i.e., friendship \& romantic relationship).

Wim Meeus is Professor of Adolescent Development Utrecht University and Developmental Psychology Tilburg University. Research interests are individual development, personal relationships and problem behavior in adolescence. The present study was supported by grants of The Netherlands Organisation for Scientific Research (NWO). 